\title{
Heterotaxy syndrome: This is the left, right?
}

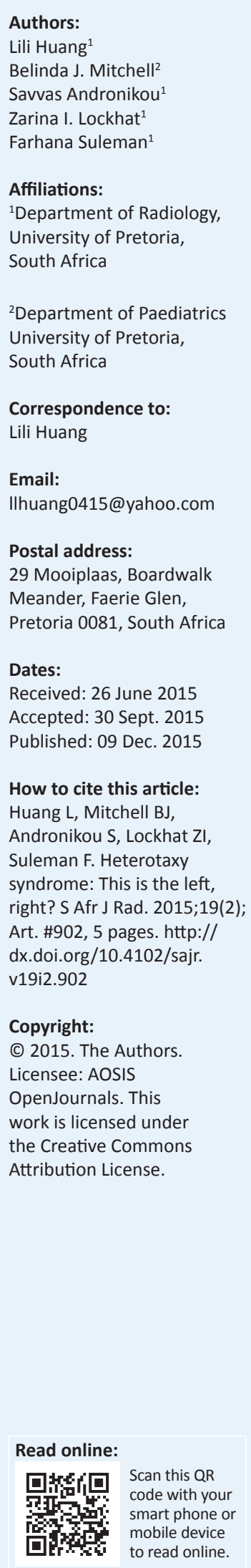

Heterotaxy syndrome is a rare and complex disorder of the chest and abdominal organ arrangements, and presents a diagnostic challenge to the radiologist. This article describes the morphological characteristics of heterotaxy and situs abnormalities, in particular left and right atrial isomerism, and suggests an approach in evaluating the spectrum of abnormalities associated with heterotaxy syndromes, using appropriate imaging modalities.

\section{Introduction}

Heterotaxy includes a spectrum of malformations involving abnormal right-left axis determination. Thoraco-abdominal visceral laterality is deranged, often accompanied by midline defects of the face and brain. The incidence of heterotaxy is 1 in 5000-7000 live births with congenital heart disease. ${ }^{1,2}$ Patients may present incidentally when a chest radiograph shows dextrocardia or a right-sided stomach bubble, or with symptoms associated with cardiac defects, intestinal obstruction or immune deficiencies. Despite current advances in medical and surgical management, the long-term prognosis remains guarded. ${ }^{1,3}$ Right isomerism has an overall 5-year survival of $30 \%-74 \%$ whereas left isomerism, owing to the less complex associated cardiac defects, fares better, with survival of between $65 \%$ and $84 \% .{ }^{1,2}$

Various human genes associated with heterotaxy syndrome have been identified with varying phenotypical expression. . $^{1,4}$ There are four embryonic phases where left-right development may be affected: (1) breaking of left-right symmetry at early embryogenesis; (2) transmission of asymmetric signals from the node to the lateral plate mesoderm; (3) asymmetric gene expression in the left lateral plate mesoderm; and (4) left-right asymmetric morphogenesis of the internal organs. If alteration occurs at the initial stages of embryogenesis, there is usually complete inversion of the left-right axis (situs inversus), whilst interference at a later stage might result in only some organs being affected, with randomised positioning of organs along the left-right axis (heterotaxy) and mirror image duplication of organs (isomerism). ${ }^{4}$

The term 'situs' refers to the position of the atria and viscera in relation to the midline. Situs solitus is the usual arrangement of organs and vessels within the body, inferred when the systemic atrium, trilobed lung, liver, gallbladder and inferior vena cava (IVC) are positioned on the right; and the pulmonary atrium, bilobed lung, aortic arch, cardiac apex and stomach bubble are positioned on the left. In situs inversus, the anatomical arrangement of these structures is reversed and is the mirror image of situs solitus. Any other presentation with visceral malposition/dysmorphism associated with indeterminate atrial arrangement and vascular anomalies is termed situs ambiguous or heterotaxy. 3,5

Heterotaxy is subdivided into right or left isomerism, according to the atrial appendage anatomy. The atrium with a broad-based appendage receiving blood from the IVC, is called the systemic or right atrium. The atrium with a smaller, narrower appendage receiving blood from the pulmonary veins, is the pulmonary or left atrium. ${ }^{3,5}$ Common morphological characteristics of right and left isomerism are summarised in Table $1 .^{1,2}$

Thorough radiological examination of every organ system is needed to delineate all rotational abnormalities and their associated complications in order to plan optimal management. ${ }^{1,2}$ The appropriate imaging approach to heterotaxy is summarised in Figure 1.,6,7

\section{Imaging findings \\ Chest \\ Cardiovascular}

The presence or absence of normal situs solitus can be determined on chest radiography, as well as certain features that are commonly seen in heterotaxy, such as dextrocardia (Figure 2) or mesocardia (Figure 3), right-sided stomach bubble, right-sided aortic arch and midline liver (Figure 4). ${ }^{1,3}$ 
TABLE 1: Common morphological characteristics of right and left isomerism.

\begin{tabular}{|c|c|c|}
\hline Characteristics & Right isomerism & Left isomerism \\
\hline Cardiovascular malformations & $\begin{array}{l}\text { single atrium with bilateral right atrial appendages } \\
\text { mesocardia/dextrocardia } \\
\text { single right ventricle } \\
\text { double-outlet right ventricle } \\
\text { atrioventricular discordance } \\
\text { right-sided aortic arch } \\
\text { malposition of the great arteries } \\
\text { pulmonary stenosis/atresia } \\
\text { bilateral SVCs } \\
\text { total pulmonary venous drainage }\end{array}$ & $\begin{array}{l}\text { bilateral left atrial appendages } \\
\text { unbalanced ventricles } \\
\text { partial anomalous pulmonary venous drainage } \\
\text { persistent left IVC draining into the left atrium } \\
\text { interrupted hepatic portion of IVC } \\
\text { left SVC }\end{array}$ \\
\hline Other malformations/dysfunction & $\begin{array}{l}\text { bilateral right-sided lungs and bronchi: short bronchus, } \\
\text { trilobed lungs } \\
\text { asplenia } \\
\text { symmetrical liver } \\
\text { right-sided stomach } \\
\text { intestinal malrotation }\end{array}$ & $\begin{array}{l}\text { bilateral left-sided lungs and bronchi: long bronchus, bilobed lungs } \\
\text { polysplenia } \\
\text { midline liver } \\
\text { extra-hepatic biliary atresia/hypoplasia } \\
\text { extra-hepatic portal vein atresia } \\
\text { intestinal malrotation }\end{array}$ \\
\hline
\end{tabular}

Source: Table from electronic poster C1214 (with permission) ${ }^{1}$

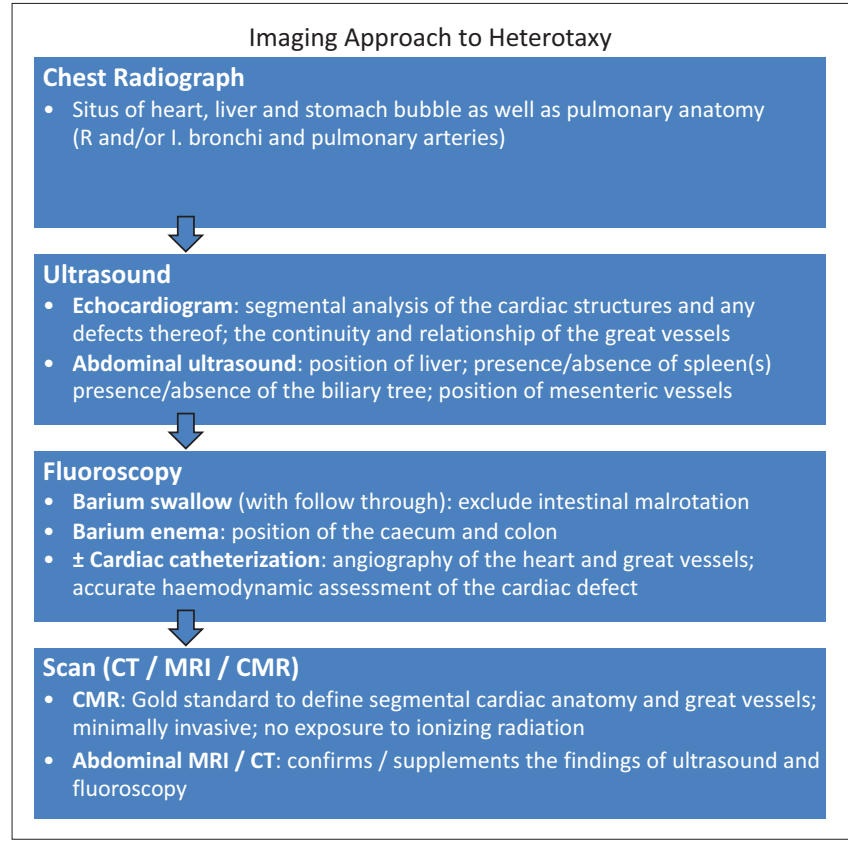

FIGURE 1: Flow diagram illustrating the imaging approach to heterotaxy syndrome.

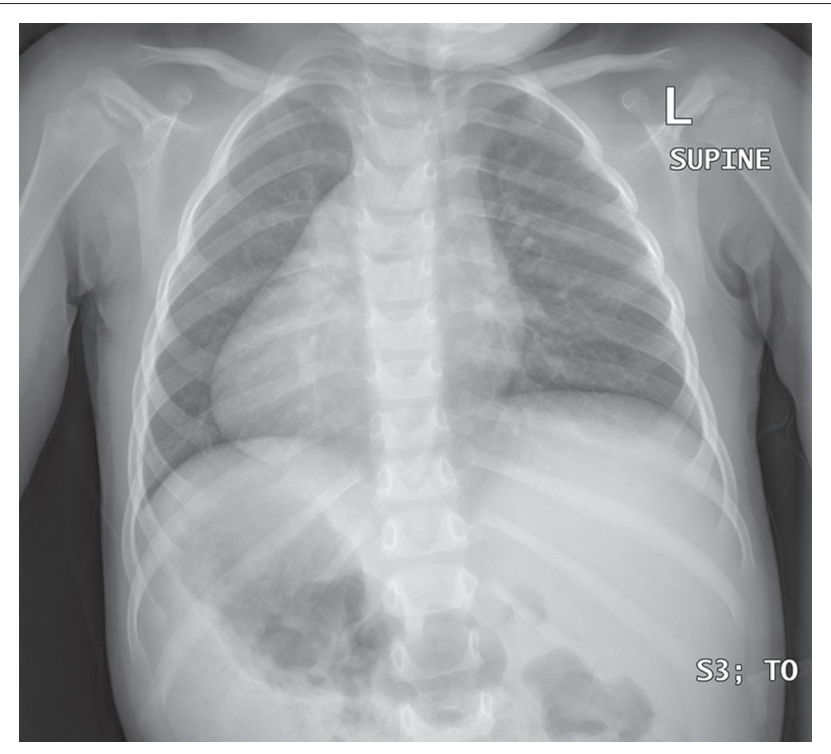

FIGURE 2: Frontal chest radiograph demonstrating dextrocardia with right-sided aortic arch and right-sided stomach bubble in right isomerism.

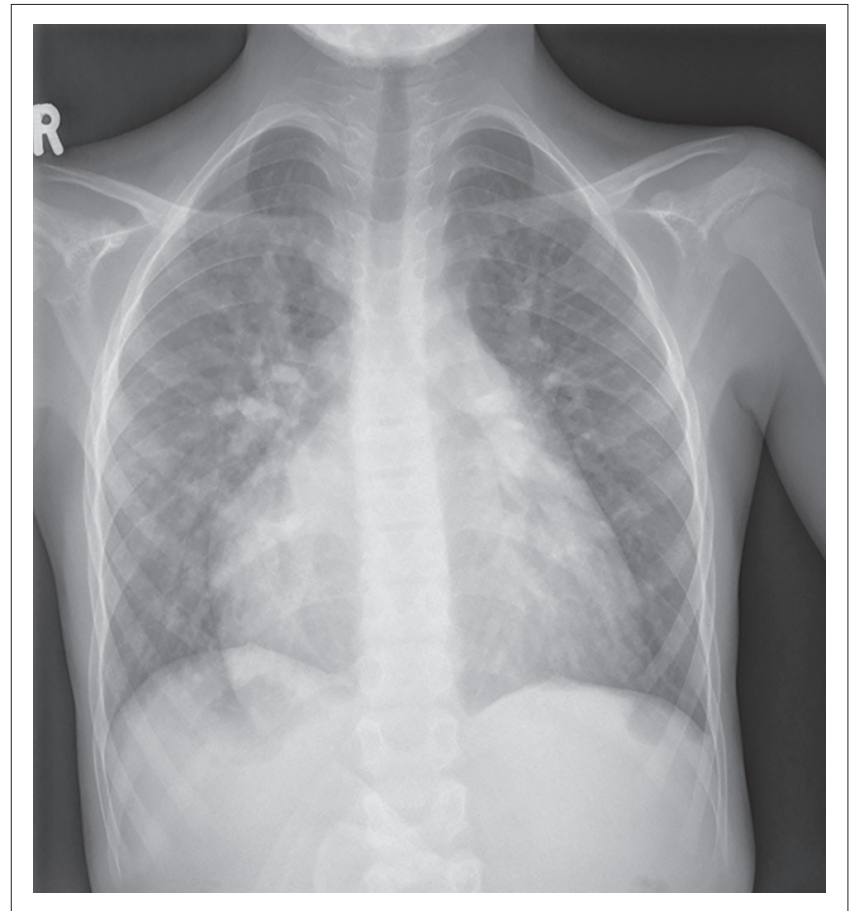

FIGURE 3: Frontal chest radiograph demonstrating mesocardia with right-sided stomach bubble with prominent pulmonary vasculature in right isomerism.

Echocardiography defines the intracardiac and cardiovascular anatomy. ${ }^{1,2}$ Right or left isomerism is defined by the arrangement of the atrial appendages. There are four possible atrial appendage arrangements (Figure 5). ${ }^{1,8}$ Right isomerism (Figure 6) is characterised by bilateral broad-based pyramidal-shaped right atrial appendages, whereas left isomerism (Figure 7) is identified by bilateral finger-like left atrial appendages. ${ }^{1,8}$ Right isomerism commonly presents with atrioventricular canal defects (AVCD) (Figure 8), pulmonary stenosis or atresia, and transposition of the great arteries (TGA), with or without double outflow from the right ventricle (DORV) (Figure 9). ${ }^{1}$ Heart defects associated with left isomerism tend to be less complex. Total anomalous pulmonary venous return (TAPVR) is common in both forms of isomerism.

While echocardiography remains the first-line investigation, cardiovascular magnetic resonance (CMR) is now the gold 


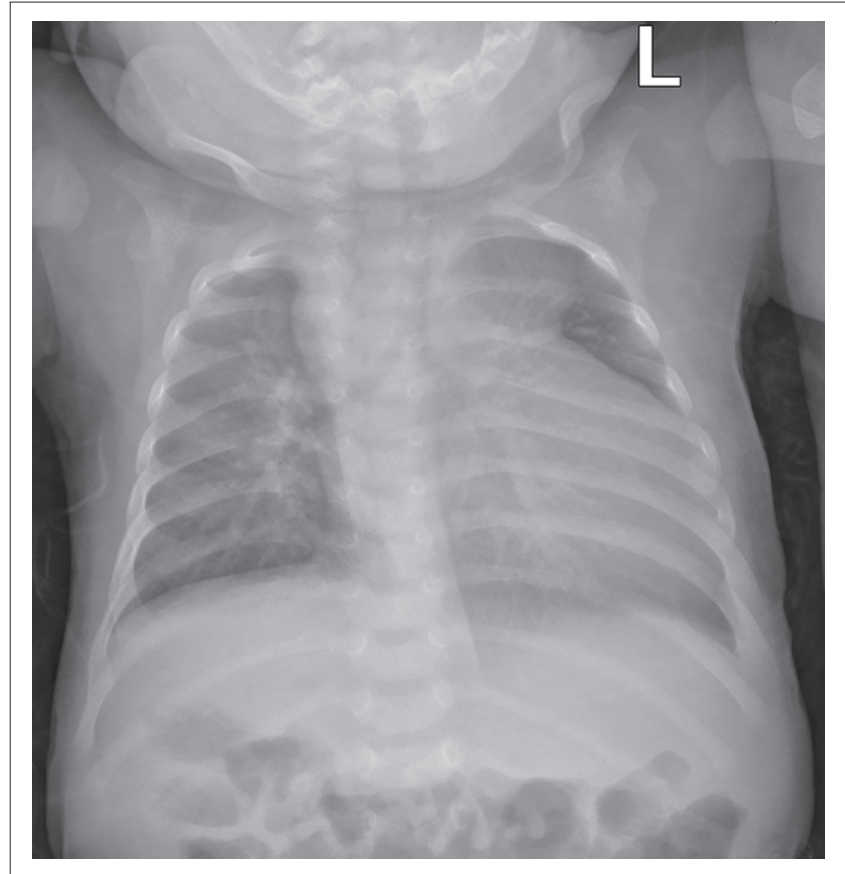

FIGURE 4: Frontal chest radiograph demonstrating cardiomegaly with left-sided stomach bubble in left isomerism.

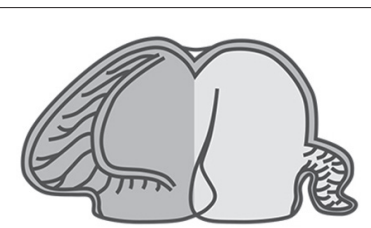

Usual arrangement

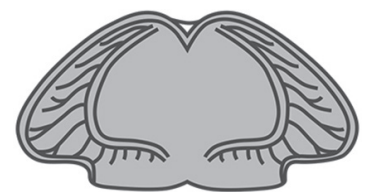

Isomerism of right appendages

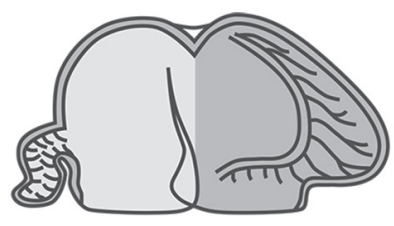

Mirror-imaged arrangement

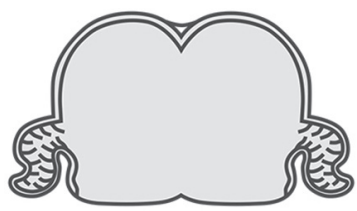

Isomerism of left appendages
FIGURE 5: Illustration of four possible atrial appendages.

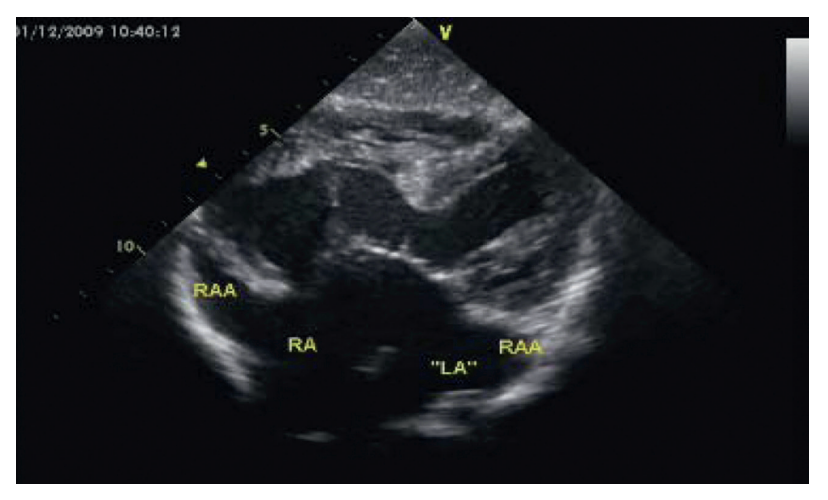

FIGURE 6: 2D echocardiogram 4-chamber view demonstrating pyramidalshaped bilateral right atrial appendages.

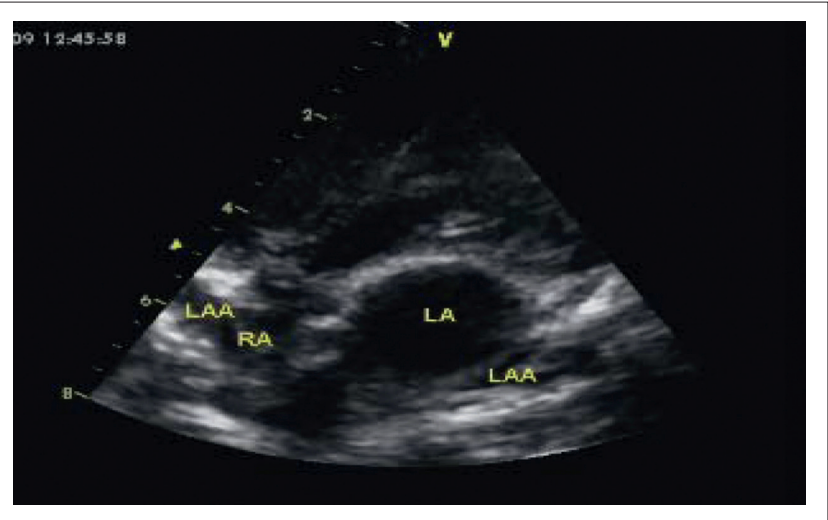

FIGURE 7: 2D echocardiogram 4-chamber view demonstrating bilateral fingerlike atrial appendages in left isomerism.

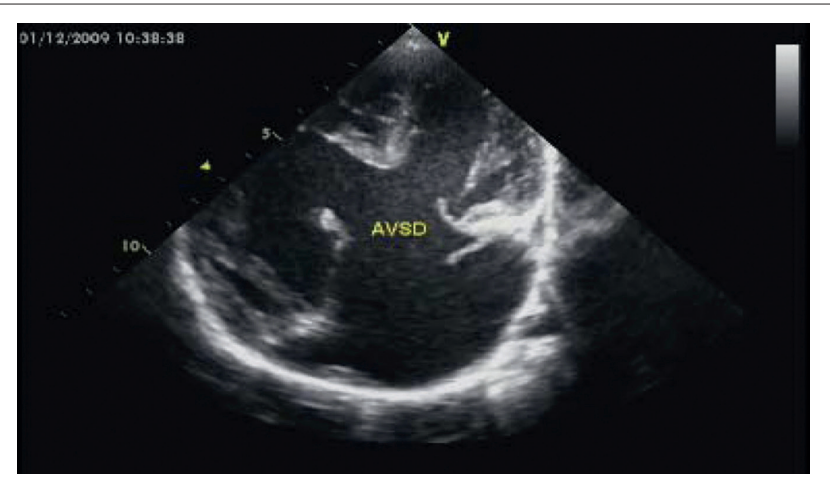

FIGURE 8: 2D echocardiogram 4-chamber view demonstrating a large atrioventricular septal defect.

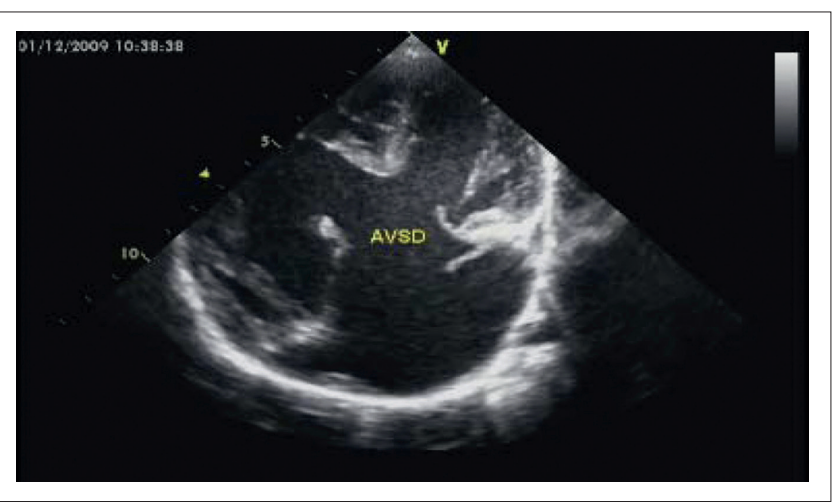

FIGURE 9: 2D echocardiograph colour Doppler 4-chamber view demonstrating classic double-outlet right ventricle.

standard imaging modality in this context and is useful for assessment of cardiac and vascular structures and function. Furthermore, CMR and computed tomography (CT) are both useful for the study of other organs within the chest and abdominal cavities. ${ }^{3}$ Echocardiography and CMR are preferred for the absence of ionising radiation. ${ }^{5}$ However, the newer multidetector CT (MDCT) scanners have the advantage of evaluating cardiac morphology, coronary vasculature, great vessels angiography and abdominal viscera at acceptable radiation doses. ${ }^{5}$ 
If cardiac CT or CMR are not available or not conclusive, cardiac catheterisation can be done to further delineate the cardiac anatomy as well as the location of the aorta and IVC for surgical planning, as was done in our hospital. Right isomerism is characterised by bilateral morphological right pulmonary arteries, as well as bilateral superior vena cavas (SVCs) (see the following video: https://youtu.be/bQggzTXTkDQ) ${ }^{1}$ and persistent left-sided IVC (see the following video: https:/ / youtu.be/Q2ZQOrhCK9g). ${ }^{1}$ The abdominal aorta and IVC are positioned on the ipsilateral side of the midline (Figure 10). Typical left isomerism is characterised by bilateral morphological left pulmonary arteries (see the following video: https://youtu.be/bvjAjwJMy9c) ${ }^{1}$ and IVC interruption at the supra-renal level with continuation as azygous or hemi-azygous to the SVC (see the following videos: https://youtu.be/b6_N5TKJldo https://youtu. be/cuzHJuHVECc). ${ }^{1}$ The abdominal aorta and IVC are located on contra-lateral sides of the midline (Figure 11). ${ }^{1,2}$ A persistent left SVC draining to the right atrium (RA) (see the following video https:/ / youtu.be/r3FGdjA-SdM) ${ }^{1}$ may also be seen in left isomerism. ${ }^{1,3}$

\section{Lungs}

Bronchopulmonary anatomy is consistent with atrial appendage structures and reinforces the diagnosis of heterotaxy. Right isomerism is associated with trilobed lungs with eparterial bronchi (Figure 12) whereas left isomerism is associated with bilobed lungs with hyparterial bronchi (Figure 13). ${ }^{1,8}$ Major lung fissures can be identified on conventional CT as hypovascular lucent bands, or on high-resolution CT as sharp lines. ${ }^{1,9}$

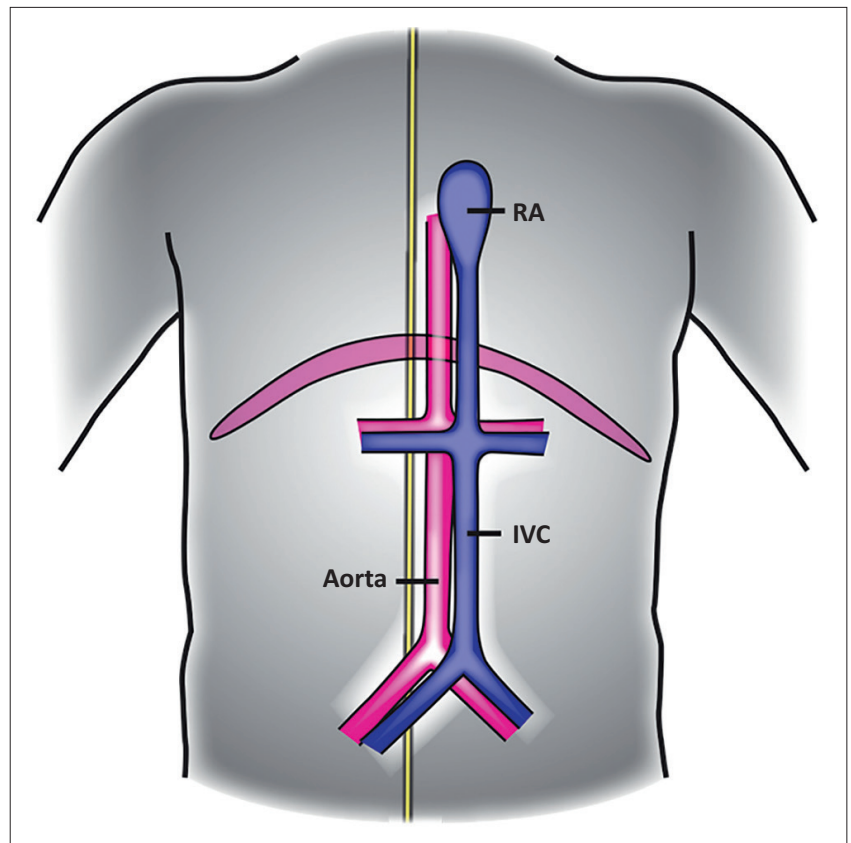

FIGURE 10: Illustration showing the position of the aorta and IVC in righ isomerism.

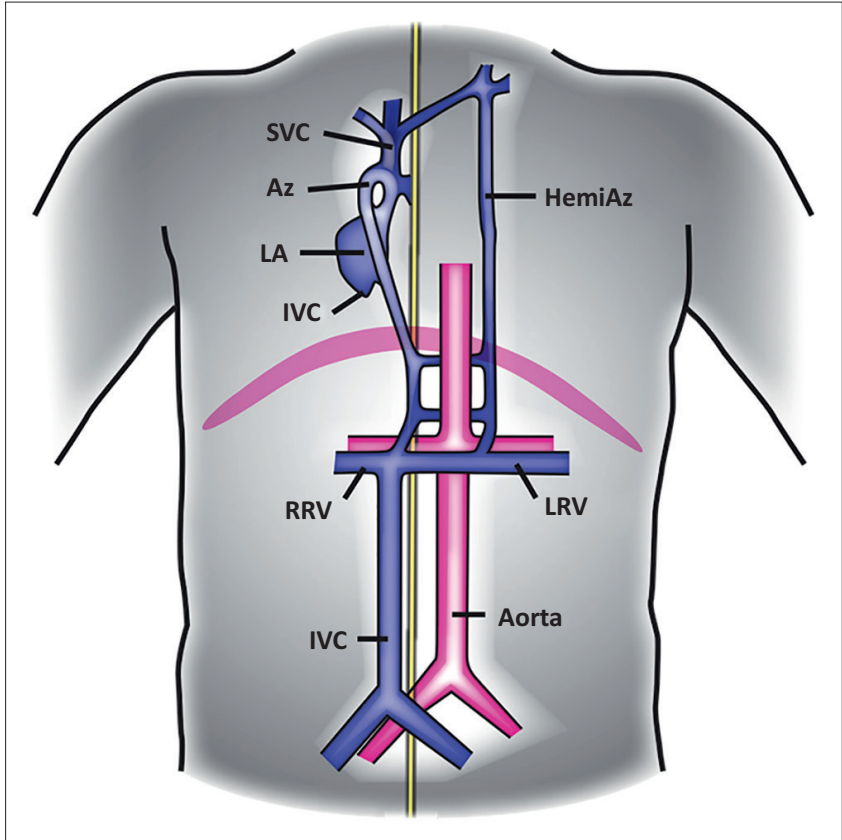

FIGURE 11: Illustration showing interrupted IVC continuing with azygous or hemizygous vein. The aorta is located on the opposite side of the midline.

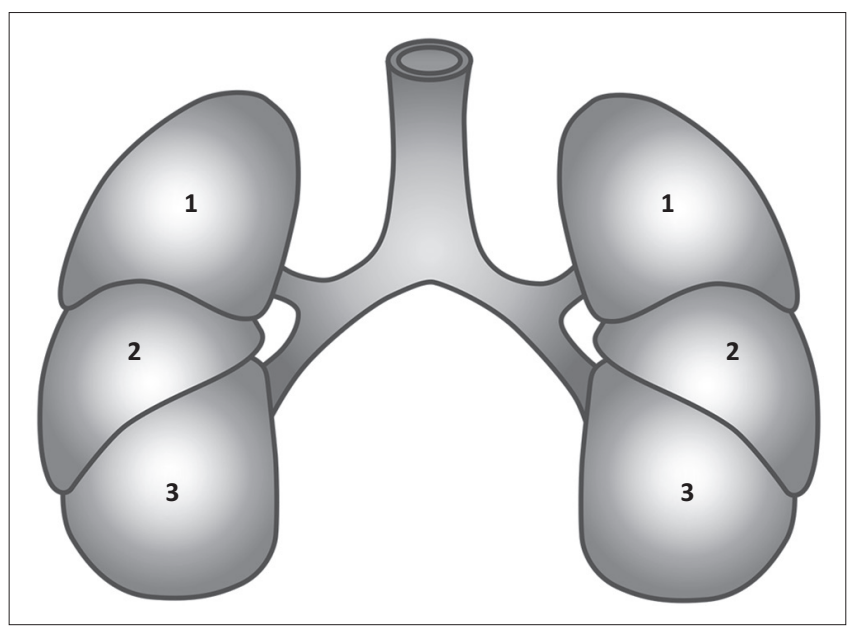

FIGURE 12: Illustration of trilobed lungs with eparterial bronchus in right isomerism.

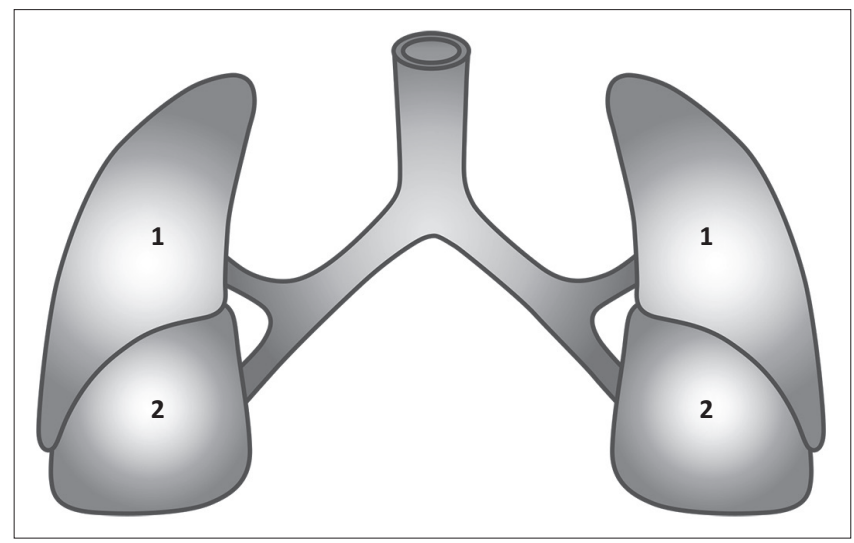

FIGURE 13: Illustration of bilobed lungs with hyparterhal bronchus in lef isomerism. 


\section{Abdomen}

Abdominal ultrasound is performed to determine the presence or absence of the spleen, the position of the liver, the presence and position of the gallbladder, and the position of the mesenteric arteries. ${ }^{1,3}$

Asplenia in right isomerism has the complication of increased risk of infection. Polysplenia in left isomerism is more common in female subjects. ${ }^{3}$ There may be hyperclefting of the spleen or numerous separate splenules (from 5 to 16) located in the region of the greater curvature of the stomach. ${ }^{10}$ Whilst the anatomy described is most typical, there is enormous variability and the splenules are not necessarily nonfunctional. ${ }^{7,10}$

Intestinal malrotation occurs in both right and left isomerism, with a slightly higher incidence in right isomerism. Fluoroscopic upper gastrointestinal examination (such as barium meal with follow-through) can show the duodenal and jejunal locations; there is often mal- or non-rotation with malposition of the duodenal-jejunal junction (DJJ) but the position of the small bowel beyond the DJJ is variable. ${ }^{7,10}$ CT and MRI may be necessary if further anatomical detail is required..$^{1,3}$

There is a direct association of bowel malrotation with abnormal morphology, malposition and inversion of the pancreas as both develop embryologically in the dorsal mesogastrium..$^{10}$ It is also important to be aware of the position of the pre-duodenal portal vein and mesenteric arteries and veins if surgical procedures are to be performed. The latter vessels are useful as a marker for malrotation..$^{7,10}$

\section{Conclusion}

Heterotaxy syndrome is associated with serious congenital heart defects as well as abnormalities in many other organ systems. Accurate and timeous investigation with appropriate imaging can greatly improve patient outcomes. As cardiac surgical techniques advance with increasing patient survival, so too will the need to investigate and address the many extra-cardiac systems involved.

\section{Acknowledgements}

This article was adapted from an electronic poster entitled 'This is the left, right?' presented at the European Congress of Radiology in Vienna, Austria, in 2013.

\section{Competing interests}

The authors declare that they have no financial or personal relationships which may have inappropriately influenced them in writing this article.

\section{Authors' contributions}

L-L.H. (University of Pretoria) wrote literature review, prepared images. B.J.M. (University of Pretoria) clinical details and images. F.E.S. (University of Pretoria) edited the document, selected images, coordinated between authors and university regarding videos. S.A. (University of Pretoria) assisted with layout, gave idea of the manuscript. Z.L. (University of Pretoria) coordinated between various authors and contributed to final editing

\section{References}

1. Huang L, Mitchell L, Andronikou S, Suleman F, Lockhat Z. This is the left, right? Poster session presented at: European Congress of Radiology; 2013 Mar 7-11; Vienna, Austria. http://dx.doi.org/10.1594/ecr2013/C-1214

2. Shiraishi I, Ichikawa H. Human heterotaxy syndrome - From molecular genetics to clinical features, management, and prognosis. Circ J. 2012;76:2066-2075. PMID: 22864291, http://dx.doi.org/10.1253/circj.CJ-12-0957

3. Applegate KE, Goske MJ, Pierce G, Murphy D. Situs revisited: Imaging of the heterotaxy syndrome. Radiographics. 1999;19:837-852. PMID: 10464794, http:// dx.doi.org/10.1148/radiographics.19.4.g99j131837

4. Deng $\mathrm{H}$, Xia $\mathrm{H}$, Deng $\mathrm{S}$. Genetic basis of human left-right asymmetry disorders. Expert Rev Mol Med. 2014;16:1-24. http://dx.doi.org/10.1017/erm.2014.22

5. Balan A, Lazoura O, Padley SP, Rubens $M$, Nicol ED. Atrial isomerism: A pictorial review. J Cardiovasc Comput Tomogr. 2012;6:127-136. PMID: 22398009, http:// dx.doi.org/10.1016/j.jcct.2011.10.019

6. Lapierre C, Dery J, Guerin R, Viremouneix L, Dubois J, Garel L. Segmental approach to imaging of congenital heart disease. Radiographics. 2010;30:397-411. PMID: 20228325, http://dx.doi.org/10.1148/rg.302095112

7. Newman B, Koppolu R, Murphy D, Sylvester K. Heterotaxy syndromes and abnormal bowel rotation. Pediatr Radiol. 2014;44:542-551. PMID: 24419494 $\mathrm{http}: / / \mathrm{dx}$.doi.org/10.1007/s00247-013-2861-4

8. Jacobs JP, Anderson RH, Weinberg PM, et al. The nomenclature, definition and classification of cardiac structures in the setting of heterotaxy. Cardiol Young. 2007;17(Suppl. 2):1-28. PMID: 18039396, http://dx.doi.org/10.1017/ S1047951107001138

9. Hayashi K, Aziz A, Ashizawa K, Hayashi H, Nagaoki K, Otsuji H. Radiographic and CT appearances of major fissures. Radiographics. 2001;21:861-874. PMID: 11452059, http://dx.doi.org/10.1148/radiographics.21.4.g01j|24861

10. Abreu A, Nieto-Morales ML, Margarita F. Heterotaxy syndrome in a young adult. Am J Clin Med. 2012;9:36-44. http://www.aapsus.org/userfiles/files/ajcm8.pdf 